\title{
QUERATOPLASTIA PENETRANTE PROTEGIDA: TÉCNICA QUIRÚRGICA Y RESPUESTA DEL ENDOTELIO
}

\section{PROTECTED PENETRATING KERATOPLASTY: SURGICAL TECHNIQUE AND ENDOTHELIAL RESPONSE}

\author{
LÓPEZ-PLANDOLIT $\mathrm{S}^{1}$, ETXEBARRÍA J ${ }^{1}$, ACERA A ${ }^{2}$, CASTIELLA G ${ }^{3}$, DURÁN JA ${ }^{4}$
}

\section{RESUMEN}

Objetivo: Describir la técnica y conocer la seguridad de una cirugía de queratoplastia penetrante protegida (QPP).

Métodos: Se describe una técnica de QPP. Se compara la evolución postoperatoria del endotelio corneal de 17 ojos intervenidos con esta técnica, comparándola con la de 24 ojos intervenidos con queratoplastia penetrante estándar $(\mathrm{QP})$, en tres periodos de tiempo: 3-6 meses, 7-12 meses y más de 12 meses. Para el análisis estadístico se realizó el test no paramétrico de la U de Mann-Whitney.

Resultados: En ninguno de los casos intervenidos con técnica de QPP se apreció extrusión de tejidos o estructuras intraoculares. El recuento endotelial no mostró diferencia estadísticas en el período de 36 meses $(\mathrm{QP}=2.086 \mathrm{DE} 566 ; \mathrm{QPP}=1.858 \mathrm{DE} 671$; $\mathrm{p}=0,2702)$ y el de más de 12 meses $(\mathrm{QP}=1.574$ $\mathrm{DE} 745 ; \mathrm{QPP}=1.419 \mathrm{DE} 810 ; \mathrm{p}=0,2882)$. Existió diferencia significativa en el período de 7-12 meses $(\mathrm{QP}=2.255$ DE 831; $\mathrm{QPP}=1.569 \mathrm{DE} 623 ; \mathrm{p}=$ $0,0397)$.

Conclusiones: La QPP que se describe puede reducir el riesgo de ciertas complicaciones perquirúrgi-
ABSTRACT

Purpose: To describe the technique and to evaluate the safety of protected penetrating keratoplasty (PPK).

Methods: A technique for penetrating keratoplasty is described. The postoperative endothelial cell counts of 17 eyes in which this operative technique was used were compared with those in 24 eyes in whom the standard operative technique for penetrating keratoplasty (PK) was used. The post-operative time periods were grouped as follows: 3-6 months, 7-12 months and $>12$ months. For statistical analysis, the Mann-Whitney U non-parametric test was employed.

Results: There was no case where tissue extrusion occurred during the procedure. The endothelial cell count was similar in both groups for the 3-6 month period $(\mathrm{PK}=2,086$, DS 566; $\mathrm{PPK}=1,858$, DS 671; $\mathrm{p}=0.2702)$ and $>12$ months period $(\mathrm{PK}=1,574$, DS $745 ; \mathrm{PPK}=1,419$, DS 810; $\mathrm{p}=0.2882$ ). There was a significant difference in the 7-12 month period (PK $=2,255$, DS 831; PPK = 1,569, DS 623; $p=0.0397$ ). Conclusions: The described technique of PPK may reduce the risk of per-operative complications.

\footnotetext{
Recibido: 1/3/07. Aceptado: 6/3/08.

Instituto Clínico-Quirúrgico de Oftalmología. Bilbao. España.

1 Licenciado en Medicina. Hospital de Cruces.

2 Licenciado en Biología.

3 Licenciado en Medicina.

4 Doctor en Medicina. Universidad del País Vasco.

Correspondencia:

Silvia López-Plandolit

Instituto Clínico-Quirúrgico de Oftalmología

Cl. Virgen de Begoña, 34

48006 Bilbao

España

E-mail: silviaplandolit@terra.es
} 
cas. El endotelio no muestra un sufrimiento significativo cuando se compara con la técnica de QP estándar.

Palabras clave: Queratoplastia penetrante, endotelio corneal, técnica quirúrgica.

\section{INTRODUCCIÓN}

Actualmente, y pese a que la queratoplastia penetrante (QP) sigue siendo la técnica estándar de transplante corneal, cada vez están adquiriendo mayor importancia las queratoplastias lamelares. Uno de los motivos por los que se están imponiendo estas técnicas es por la mayor seguridad quirúrgica al mantener mejor la integridad estructural ocular durante la intervención. Sin embargo, las queratoplastias lamelares no pueden ser aplicadas en caso de afectación total del espesor corneal. Para estos casos, y en especial cuando existe un mayor riesgo quirúrgico asociado a la cirugía penetrante (ojos con alteraciones importantes del segmento anterior, por ejemplo), la búsqueda de una mayor seguridad quirúrgica nos lleva al resurgimiento de las técnicas protegidas de queratoplastia (QPP).

Las técnicas protegidas de queratoplastia fueron descritas por primera vez en 1937 por Filatov (1), y recientemente ha sufrido algunas variantes (2). Básicamente, estas variantes quirúrgicas buscan evitar una apertura de toda la córnea de forma simultánea, reduciendo el riesgo de extrusión de las estructuras intraoculares.

En este estudio se describe una técnica de queratoplastia protegida y estudiamos el recuento endotelial en el seguimiento del postoperatorio, comparándolo con el de la queratoplastia penetrante tradicional.

\section{SUJETOS, MATERIAL Y MÉTODOS}

Presentamos un estudio retrospectivo de 41 ojos (correpondientes a 41 pacientes) sometidos a dos técnicas distintas de queratoplastia:

- Queratoplastia penetrante (QP): $n=24$.

- Queratoplastia penetrante protegida (QPP): $n=17$.

La microscopía endotelial se realizó con un instrumento Topcon SP-2000P (Topcon, Tokio, Japón). Se obtuvieron las exploraciones en tres etapas del postoperatorio:
Damage to the endothelium is not increased compared with that seen following the standard PK procedure (Arch Soc Esp Oftalmol 2008; 83: 231-236).

Key words: Penetrating keratoplasty, corneal endothelium, surgical technique.

- Corto plazo: entre los 3 y 6 meses (media $=5$ meses).

- Medio plazo: entre los 7 y los 12 meses $($ media $=11$ meses $)$.

- Largo plazo: más de 12 meses (media $=24,5$ meses).

La edad media fue de 59 DE 20,66 años en el grupo QP y de 73 DE 13,54 años en el grupo QPP (gráf. 1). En cuanto a la patología causal, también difería entre los distintos grupos (gráf. 2). Así:

- En el grupo de QP, la patología predominante era la distrofia endotelial de Fuchs, seguido por el queratocono y en tercer lugar enfermedad corneal herpética.

- En el grupo de QPP predominaba la descompensación endotelial secundaria a cirugías previas.

El tiempo medio de conservación de la córnea fue de 3,36 días, sin diferencias estadísticas entre ambos grupos.

Para el análisis estadístico se realizó el test no paramétrico de la U de Mann-Whitney por disponer de una $\mathrm{N}$ inferior a 30 , considerando un nivel de significación de $\mathrm{P}<0,05$.

\section{Técnica quirúrgica}

La queratoplastia de incisión limitada se realizó con anestesia peribulbar asociada de manitol $10 \%$

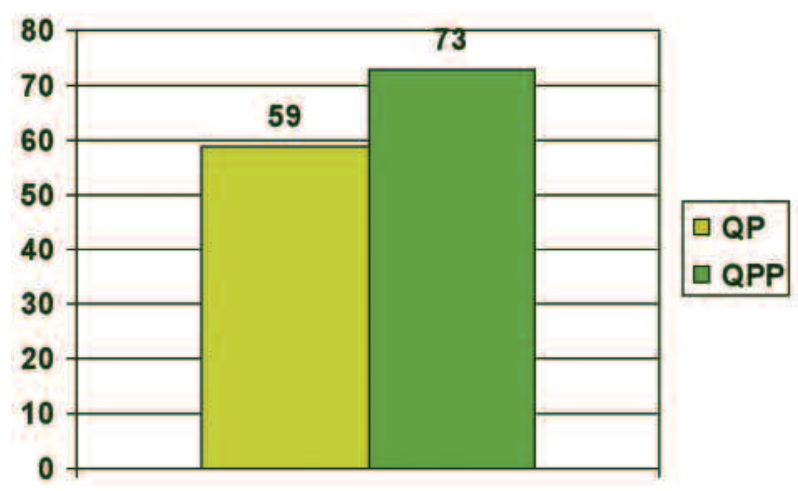

Gráf. 1: Media de edad en ambos grupos. 


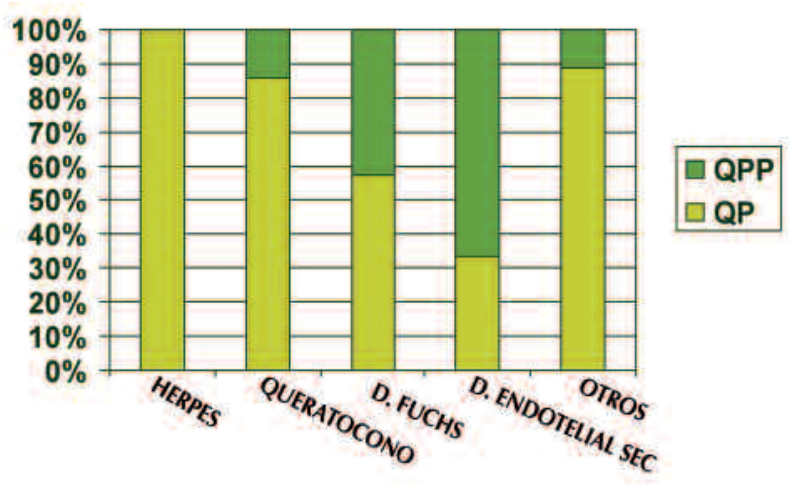

Gráf. 2: Patología causal de la queratoplastia en ambos grupos.

intravenoso. La cirugía se inicia de una manera tradicional:

1. La córnea donante es trepanada con un «punch» y la córnea receptora es trepanada con un trépano de succión, dejando una marca profunda sin entrar a cámara anterior.

2. No necesita anillo escleral. El diámetro de la trepanación en el receptor es entre 7,5-7,75 mm, ambos con una trepanación del donante de 0,25-0,5 mm mayor.

3. Se recomienda marcar las referencias en el anillo receptor para posición de los puntos. Una vez hecho el surco, el epitelio de la córnea receptora es eliminado. Se accede a cámara anterior por paracentésis de $1 \mathrm{~mm}$ a las 11 horas.

4. La cámara se llena con viscoelástico de alta densidad (figs. 1 y 2).

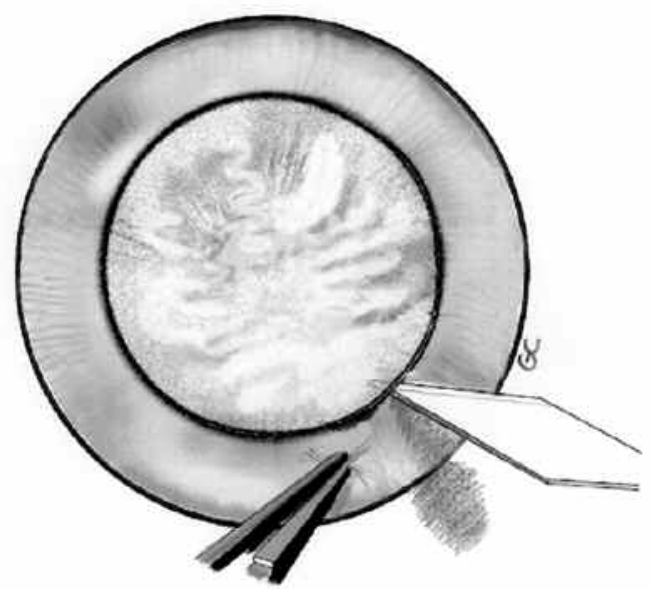

Fig. 1: Tras una trepanación profunda no perforante, se realiza una incisión inicial a las 11 horas.

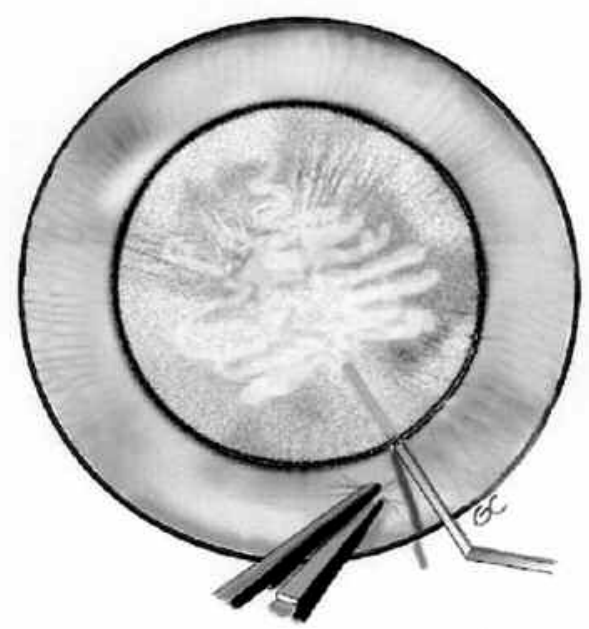

Fig. 2: Introducción de viscoelástico de alta densidad.

5. En esta etapa pueden ser realizadas maniobras tales como sinequiotomía, iridoplastia o manipulación de la LIO.

6. Se realiza otra nueva incisión a las 10 horas evitando el contacto con la incisión previa. Desde la primera incisión se avanza con tijera hasta las 4 horas. En este momento será posible realizar maniobras adicionales que requieren una incisión más amplia.

7. La incisión de las 10 horas se amplía hasta las 5 horas (figs. 3 y 4 ).

8. Se coloca viscoelástico en la superficie de la córnea receptora y sobre ella se coloca el injerto

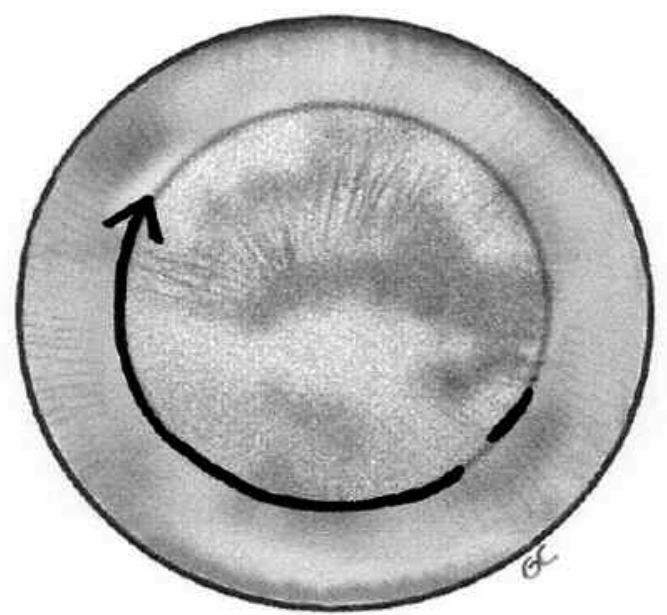

Fig. 3: Tras una segunda incisión a las 10 horas, desde la primera incisión se avanza con la tijera hasta las 4 horas. 


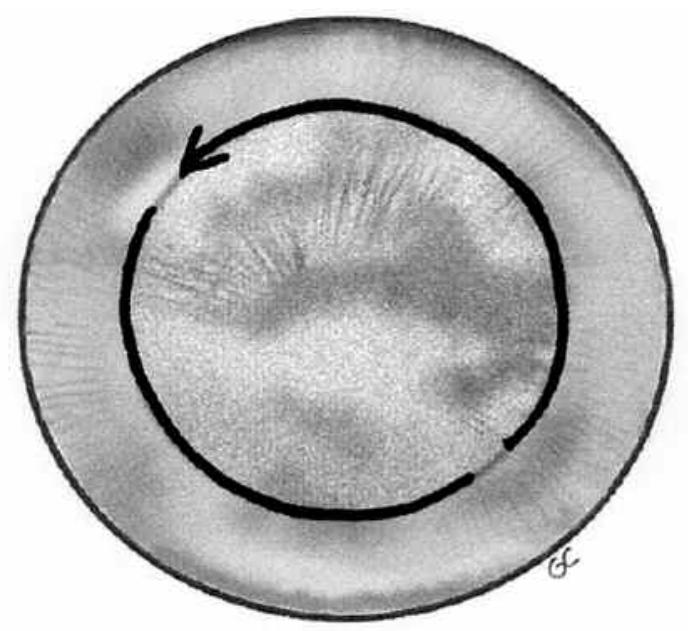

Fig. 4: La incisión de las 10 horas es ampliada hasta las 5 horas. La córnea a explantar se manteniene unida por dos puentes.

que se fija con puntos simétricos a las 7,30 h y 1,30 h. (fig. 5).

9. Con los dos puntos asegurados se corta el puente entre las $10 \mathrm{~h}$ y las $11 \mathrm{~h}$ y un tercer punto se coloca en ese lugar (fig. 6).

10. Finalmente el puente entre las 4 y las $5 \mathrm{~h}$ se secciona y el botón receptor es retirado debajo del injerto manteniendo siempre viscoelástico entre ambos tejidos.

11. Se coloca un cuarto punto y luego se completa la sutura del injerto con sutura contínua (fig. 7).

La queratoplastia penetrante se realizó mediante la técnica estándar. En las dos técnicas se realizó una

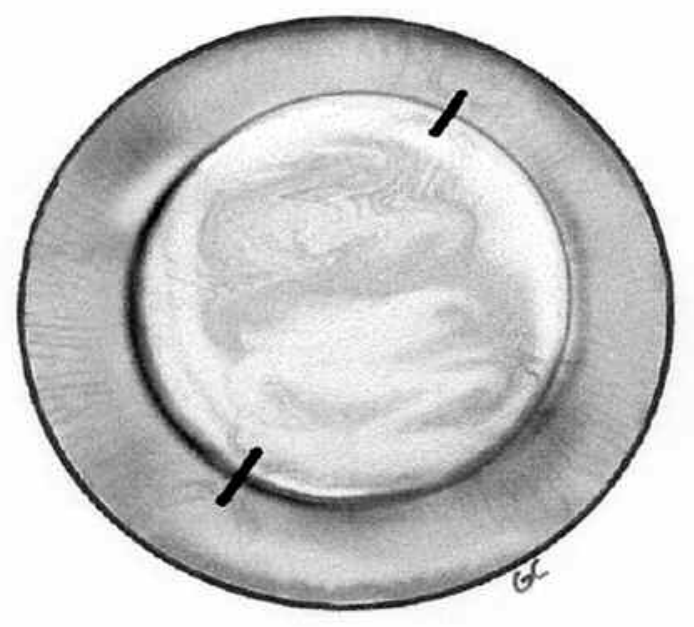

Fig. 5: Fijación del injerto con dos puntos simétricos a las 7:30 y las 13:30 horas.

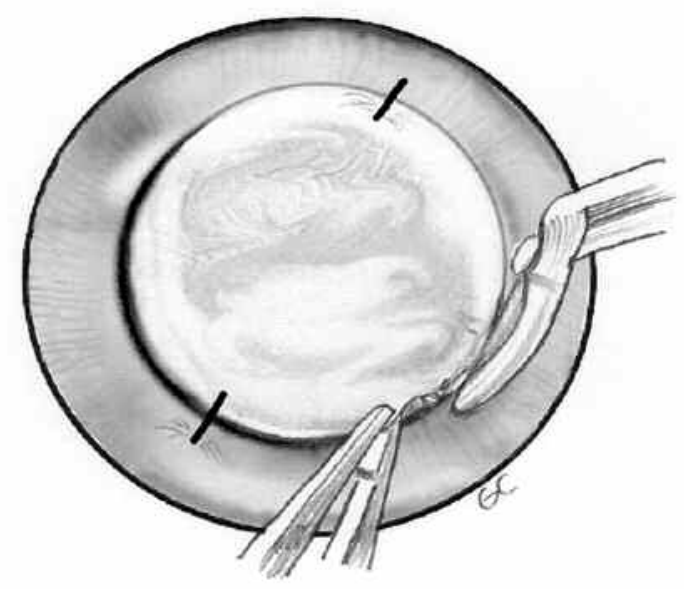

Fig. 6: Cortamos el puente del botón receptor entre las 10 y las 11 horas.

primero sutura interrumpida de 4 puntos completándola después con otros 16 puntos o con una contínua de nylon 10/0. Las intervenciones fueron realizadas por uno de los dos cirujanos (JAD y JEE).

\section{RESULTADOS}

No hubo complicaciones relevantes en ninguna de las intervenciones y el postoperario curso dentro de los límites e la normalidad. Al final del estudio se encontraban transparentes 21 córneas del grupo QP y 12 del grupo QPP.

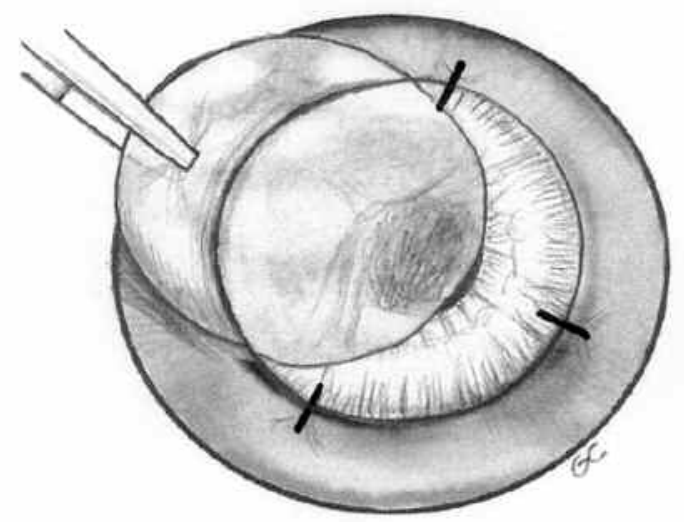

Fig. 7: Tras la tercera sutura y el corte del puente entre 4 y 5 horas, el botón receptor es retirado debajo del injerto manteniendo siempre viscoelástico entre ambos tejidos. 
Los recuentos endoteliales en los distintos periodos de exploración fueron:

- Corto plazo (3-6 meses): QP = 2.086 DE 566; $\mathrm{QPP}=1.858 \mathrm{DE} 671$. No diferencias significativas ( $\mathrm{p}=0,2702)$ (fig. 8).

- Medio plazo (7-12 meses): $\mathrm{QP}=2.255 \mathrm{DE}$ 831; QPP $=1.569$ DE 623. Diferencia significativa ( $\mathrm{p}=0,0397$ ) (fig. 9).

- Largo plazo (más de 12 meses): QP $=1574$ DE 745; QPP de 1.419 DE 810. No diferencia significativas ( $p=0,2882)$ (fig. 10).

\section{DISCUSIÓN}

Las dificultades y riesgos asociados a la queratoplastia penetrante están determinados en gran medida por la presencia de alteraciones en el segmento anterior. Para estos casos sería deseable hacer una cirugía con mínima incisión, imposible en las técnicas de queratoplastia penetrante convencionales.

Como alternativa, están surgiendo las técnicas lamelares. Sin embargo, dichas técnicas, a pesar de su contribución a la cirugía corneal, no pueden ser aplicadas en todos los casos (4).

En ciertas indicaciones con alteraciones del segmento anterior (sinequias anteriores, presencia de vítreo, lentes de cámara anterior,...) proponemos la utilización de una técnica de QPP. Hemos modificado la técnica de Filatov, interponiendo viscoelástico de alta densidad entre el injerto y la córnea del

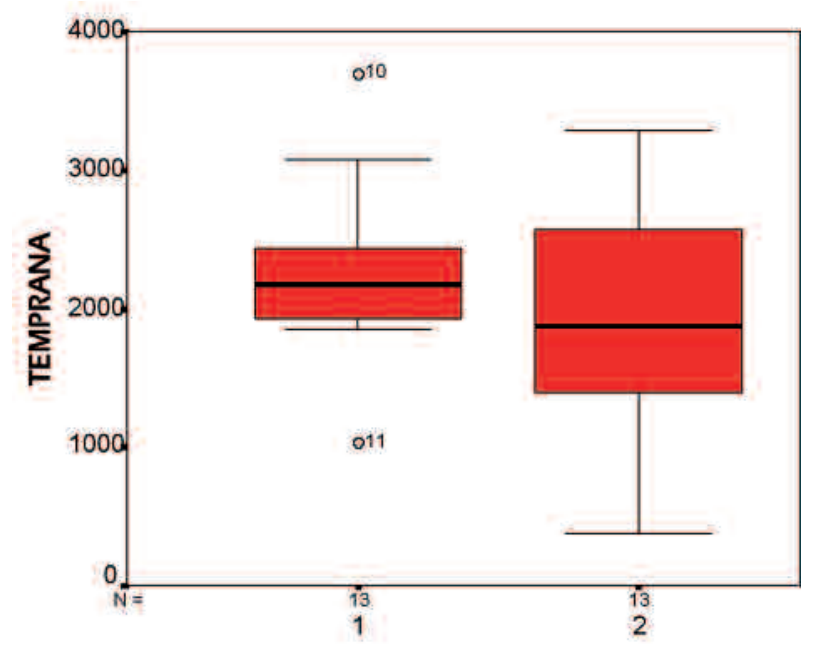

Fig. 8: Media del recuento endotelial en los primeros 6 meses en el grupo de QP (1 en el eje de abscisas) y QPP (2 en el eje de abscisas).

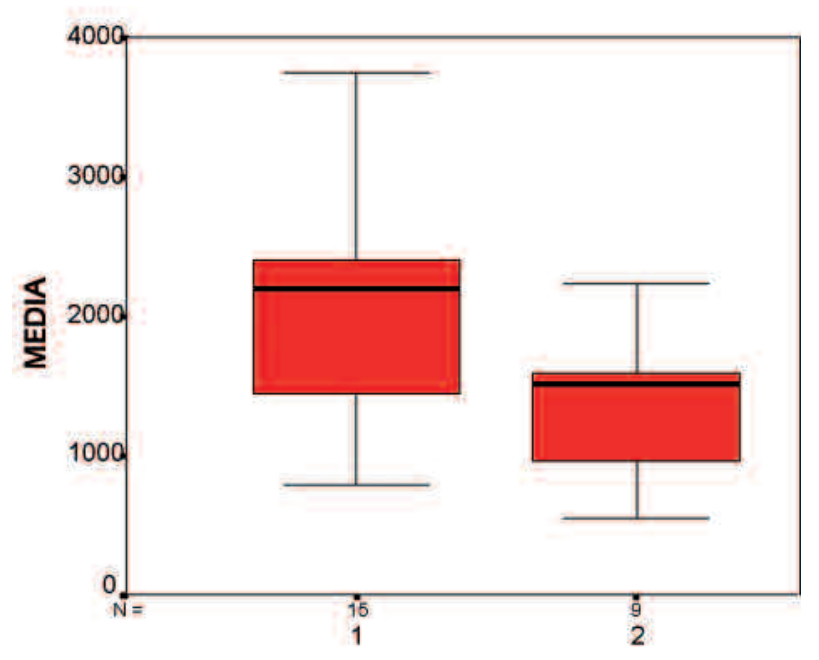

Fig. 9: Media del recuento endotelial entre los 6 y 12 meses en el grupo de QP ( 1 en el eje de abscisas) y QPP (2 en el eje de abscisas).

paciente, en un intento de disminuir el traumatismo endotelial donante, puesto que ésta era la mayor limitación de dicha técnica.

Así, la queratoplastia de incisión limitada, aporta una mayor seguridad quirúrgica, ya que evita la total apertura de la córnea al mantener en todas las etapas, al menos dos zonas unidas al ojo, lo cual limita el riesgo de prolapso de tejidos y asegura el confinamiento de los mismos dentro del ojo. Presenta además la ventaja de no requerir instrumentos especiales y además no precisa un tiempo quirúrgi-

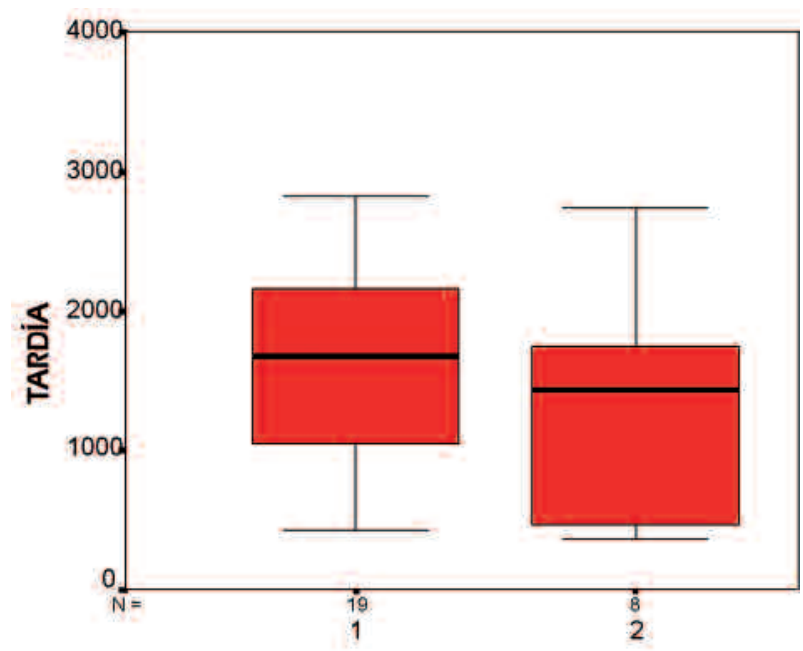

Fig. 10: Media del recuento endotelial a partir de los 12 meses en el grupo de QP ( 1 en el eje de abscisas) y QPP (2 en el eje de abscisas). 
co superior a la técnica clásica. El uso de viscoelástico de alta densidad y de manitol intravenoso aumenta la seguridad del procedimiento.

El mayor inconveniente de la técnica de QPP sería el daño del endotelio del injerto, pues éste se apoya en la córnea receptora. De hecho y a pesar de unos recuentos endoteliales no muy desfavorables, la proporción de fracasos corneales es mayor con esta técnica. No obstante, probablemente existe una influencia de la patología causal en la obtención de valores inferiores de células endoteliales (5-7). La QPP se ha utilizado en pacientes de más edad (gráf. I) y en casos más complejos, como presencia de lente de cámara anterior, alteraciones del iris, presencia de vítreo, etc. (gráf. 2). Así, en este grupo las alteraciones presentes en el segmento anterior motivaron que hiciera falta asociar la queratoplastia a otras maniobras quirúrgicas, como vitrectomía anterior, sinequiotomía, extracción del cristalino, sutura de iris, etc.

Además, debemos tener en cuenta que si en estos casos se hubiera hecho una QP tradicional hubiera habido riesgo de extrusión del contenido intraocular por la mayor manipulación de los tejidos, y un mayor apoyo endotelial en la lente u otras estructuras intraoculares durante la fase de la sutura. Al limitarse la apertura corneal resulta más fácil la manipulación intraocular y la colocación de las pri- meras suturas y se reduce el riesgo de colapso del globo ocular y de hemorragia expulsiva.

Por lo tanto, podemos concluir que esta técnica aporta mayor seguridad quirúrgica, sin disminuir significativamente el recuento endotelial del injerto. Esto permite poder recomendar esta opción quirúrgica en los casos de queratoplastia penetrante de mayor riesgo, en los que se asocian alteraciones del segmento anterior.

\section{BIBLIOGRAFÍA}

1. Filatov VP.Transplantation of the cornea. Arch Ophthalmol 1935; 13: 321-347.

2. Zaidman G. Pediatric keratoplasty. In: Rasik V. Corneal transplantation. New Delhi, India: Jaypee Brothers Medical Publishers (P) Ltd; 2002; 201-208.

3. Faktorovich EG, Rabinowitz YS. Method for safer penetrating keratoplasty in patients with low scleral rigidity. $J$ Cataract Refract Surg 1999; 25: 882-884.

4. Panda A, Bageshwar LM, Ray M, Singh JP, Kumar A. Deep lamellar keratoplasty versus penetrating keratoplasty for corneal lesions. Cornea 1999; 18: 172-175.

5. Patel SV, Hodge Do, Bourne WM .Corneal endothelium and postoperative outcomes 15 years after penetrating keratoplasty. Am J Ophthalmol 2005; 139: 311-319.

6. Bourne WM. Cellular changes in transplanted human corneas. Cornea 2001; 20: 560-569.

7. Armitage WJ, Dick AD, Bourne WM. Predicting endothelial cell loss and long-term corneal graft survival. Invest Ophthalmol Vis Sci 2003; 44: 3326-3331. 